\title{
LA LENGUA Y CULTURA CASTELLANA EN COREA
}

\author{
Dra. D. ${ }^{a}$ Amalia Roales-Nieto \\ Madrid. España
}

La Hispanidad ocupa en el mundo un espacio muy importante desde hace siglos, forma un bloque cultural, político y comercial de notable interés en la vida contemporánea actual. No pretendo en este momento, analizar lo hispánico, sino estudiar la divulgación que ha tenido lo Hispánico en Corea, país situado fuera del ámbito iberoamericano.

España hasta el momento presente, se ha ocupado, y se ocupa, de la conservación y proyección de su cultura sobre tantos pueblos de habla española, tantos pueblos que conservan nuestras tradiciones y creencias. Vomos todos los días cómo la televisión, la prensa y la radio, hablan y divulgan todo lo relativo a China, a Cuba, Nicaragua, Venezuela, Argentina o a Filipinas, intentando y consiguiendo, quizá, acercarnos más al otro lado del Atlántico con esa velocidad y superación de fronteras conseguidas por los medios de comunicación más sofisticados y modernos.

Corea es otro mundo, y sin embargo, en Corea hay un creciente interés por lo español. Supongo que sucederá lo mismo que en otros países de Extremo Oriente (me consta el interés que ahora mueve a los hispanistas filipinos por resucitar una antigua etapa de su historia casi borrada por las obligadas superposiciones de la cultura norteamericana).

Quisiera estudiar en mi trabajo el proceso que ha llevado a Corea a contactar con lo hispánico, bastante reciente en cuanto a lengua se refiere y no por ello menos interesante. Quisiera también revalorizar la Hispanidad desde un país no incluido en la órbita hispana. Corea es un nuevo horizonte en el que también se estudia la historia, la lengua y la civilización española, y soy testigo de algunos hechos que relataré más adelante.

\section{UN POCO DE HISTORIA}

Corea es una nación de riquísima tradición cultural y artística heredada secularmente y manifiesta en su espíritu creativo o en la fantasía de sus artistas. Como todo el mundo sabe, ha sido invadida múltiples veces y, por ello, fue doblemente autónoma, independiente y encerrada en si misma, dedicada, itodavía hoy! a la recuperación de su cultura ancestral y a la reunificación del país separado ideológicamente por el paralelo $38^{\circ} .^{1}$

1 El paralelo 38 en España pasa por Córdoba. 
Como nación independiente prefirió la autonomía y el aislacionismo, procurando conservar relaciones amistosas con China, su país vecino, y vivir con sus propios medios hasta mediados del siglo XVI. Es la época de los Tre Reinos: Koguryo, Paeckche y Sil-la. Esta fecha marca la época áurea. El auge y florecimiento del siglo cultural en el que surgen las obras de arte más características e independientes del talento coreano. La dinastía de los Koryo rebautizará la vieja Choson en la nueva Korea y con la dinastía de los Yi, sufrirá las invasiones más penetrantes y destructoras.

Hacia 1392, la familia Choson (última dinastía reinante en el pais) intentó moralizar el reino imponiendo, a nivel nacional, el budismo decadente y autoritario, el confucionismo como religión oficial. Este absolutismo de los monarcas se vio reforzado con el aún más fuerte de la religión que no estimaba más literatura que la clásica, y despreciaba todo lo que no fuera confucionista, oponiéndose también al progreso técnico e industrial, sinónimo, según ellos, de materialismo. A militares, comerciantes e industrales se le acusaba de herejes y de vulgares. Esta circunstancia dividió el país en varios partidos, debilitando las fuerzas interiores, dando lugar a que los japoneses invadieran el territorio coreano, por primera vez en 1591. En esta época los viajes son lentos y costosos, y, pese a todo, algunos españoles viajarán a Extremo Oriente, especialmente desde el descubrimiento de América. No olvidemos que Colón buscaba las Indias Orientales y aquel mundo rico en sedas, oro y especias. Eran las novedades aportadas por Marco Plo y tantos aventureros venecianos, turcos o napolitanos.

Los españoles llegaron a Japón. Eran los primeros misioneros católicos deseosos de ejercer su ministerio sagrado. Se quedaron allí o viajeron a Corea con el ejército invasor a las órdenes del militar Hideyoshi Toyotomi, quedándose varios años en el "país de las calmas matutias". Un español es el primer europeo que llega y permanece en Corea, es el madrileño jesuita, Gregorio de Céspedes (1551-1611), hijo del corregidor-alcalde de Madrid. Su llegada a Corea está atestiguada en interesantes cartas enviadas desde Seul a sus superiores en España y Portugal a partir de 1593. Llega el 27 de diciembre de 1553, arribando a remo a las costas coreanas el día 28. Un poco más tarde, en diciembre de 1597 y en enero de 1598 arribarán el P. Laguna y S. J. y el hermano japonés Ramón Tamura, según el jesuita Juan Ruiz de Medina.

Los Hideyoshi de Japón y los mongoles, de 1591 a 1598, arrasaron el territorio conquistado, y Corea se vio en la necesidad de trabajar para sí misma en un absoluto aislamiento. Se intentaba mejorar el sistema agrícola e industrial, e iniciar un ligero desarrollo económico. No se quería contar con otros medios pero la necesidad y las presiones externas agravaron la situación obligando al antiguo Reino de Eremitas a abrir sus puertas.

\section{SIGLO XIX}

Desde 1870 a 1890, el gobierno coreano inicia contactos diplomáticos con Japón, Estados Unidos, Gran Bretaña, Alemania, Rusia y Francia. España quedará al margen de este entorno geopolítico. China y Japón continuaban disputándose el suelo coreano, ya que

2 Se está conmemorando la llegada de S. Francisco Javier a Japón. 
su posición geográfica de enlace con el continente asiático suscitaba las codicias de continentales e insulares, incitados ambos, por las discordias internas entre los partidarios de la reina Min y los del primer ministro. Corte y gobierno se fragmentaron en subgrupos dividiendo el País y dando paso a la nueva invasión nipona en 1910. Anteriormente habían enviado tropas a la revuelta de los Tong-Hak que ocasionó en 1894 una guerra con China.

Los japoneses, en expansión, guerran en el Pacífico contra ingleses, rusos, manchúes y coreanos. Su dominio más próximo es Corea y aqui desarrollan una industria bélica que cubría sus necesidades más perentorias, el dominio de la península coreana es absoluto llegándose a prohibir, por decreto, el uso de la lengua nativa y el uso del alfabeto silábico hangul, inventado y promulgado en el siglo XV por el rey Sejong el Grande, cuarto monarca de la dinastía Choson ${ }^{3}$. Es la época del éxodo intelectual, de los refugiados en China y en Manchuria y del nacimiento en el exilio, de la primera República de Corea Libre (el primer gobierno provisional nació en la ciudad de Shanghai bajo el mandato del Dr. Syngman Rhee). Los intelectuales coreanos han de estudiar en japonés y en universidades japonesas. De estos estudios partirán los primeros contactos con la literatura española, escrita ${ }^{4}$.

\section{LO ESPAÑOL EN COREA}

Un escritor: Choi, Nam-Sun (1890-1957) dará a conocer las aventuras de don Quijote en 1915. Cervantes y su obra se leen en coreano en el núm. 4 ( 1 de enero de 1915) de la revista mensual Chong-Chun; Choi, Nam-Sun no entendía el castellano, por eso lo tradujo a su lengua materna desde la versión japonesa realizada por Matsu-Ura-Masayasu en 1913. Es una traducción resumida, pero se incluyen los episodios más importantes del texto cervantino: la aventura de los molinos de viento; la de los cabreros; el yelmo de Mambrino; la cueva de Montesinos, etc. Incluyéndose en ese número de la revista citada, una breve biografia de Cervantes. Se habla de Cervantes en los siguientes terminos:

"Miguel de Cervantes Saavedra (1547-1616) que recibió el apodo de Shakespeare de España es sin duda el mayor escritor de dicha nación, dominando con su genio las novelas y poesias. En la juventud participó en la guerra contra Turqui (sic) y alli gravemente herido perdió el brazo izquierdo"...

3 También se la conoce como dinastia Yi. Su fundador, el General Yi, Song-Gye, impuso el confucionismo en Corea.

4 Vid. Juan RUIZ DE MEDINA, S.J.: Origenes de la Iglesia Católica Coreana, enero 1566 y 1748, Roma. 1986. Consúltense también los siguientes:

Ralph M. CORY: "Same notes on Father, Gregorio de Céspedes. Korea's First European Visitor", en Transactions the Korea Asiatic Society, vol XXVII, Seul 1937, pp. 1-55.

PARK Chul Testimonios literarios de la tarea cultural de los misioneros españoles en el Lejano Oriente. Tesis doctoral. Ministerio de Asuntos Exteriores. Madrid 1986. "Estudio literario de las epistolas de Gregorio de Céspedes", en Journal Hankak, University of Foreign Studies, vol. 19, pp. 1-22. Seul 1986.

J. Franz SCHUTTE: Documentos sobre el Japón conservados en la Colección Cories de la Real Academia de la Historia. Madrid, 1961.

Jesús LÓPEZ GAY: "Las corrientes espirituales de la Misión de Japón en la segunda mitad del siglo XVl", en Misionalia Hispánica, núm. 85. CSIC. Madrid, 1972.

5 Vid. Chung-Su KIM: Don Quijote en Corea, su influencia en los escritores modernos (1915-1940) en español. Asociación Asiática de Hispanistas. Seul, 1915. 
y añade el profesor Kim, Chang-Su que "la traducción japonesa hace caso omiso de Sancho Panza".

Otro escritor hace una nueva traducción del Quijote. Se trata de Koh, Chang-Hwan. También publicó su traducción, resumida, en mayo de 1930. El tercer traductor se llamó Chae,Man-Shik. Su obra, de decir de Kim: "es más aceptable desde el punto de vista estético, ya que mezcla el humor satírico coreano con el espíritu quijotesco". Estas tres traducciones: Choi, Koh y Chae, tuvieron el valor de presentar la obra de Cervantes al público coreano, aunque no supiera castellano y sufrieran las consecuencias equívocas que puede presentar la doble traducción de un original. A partir de este momento surgen escritores que tratarán de imitar la obra cervantina, escribiendo novelas más o menos influenciadas por el Quijote, o leyendo, siempre en versión japonesa, otras obras españolas. Según Kim, "el Quijote es un modelo satírico cuyo modulo se conserva hasta hoy".

Quiero decir con esto que la influencia literaria es decisiva, aunque esta literatura sea vertida a través de una segunda lengua y pese a los inconvenientes, los intelectuales coreanos se interesan por nuestros escritores a primeros de siglo y su interés actual por el Quijote se ha podido comprobar en el Primer Congreso Internacional de Hispanitas Asiáticos en el que había una sección dedicada únicamente al estudio del Quijote (1985).

En febrero de 1925 el poeta coreano Li, Chang-Su Kim presentó una visión más general de Cervantes y de otros dramaturgos hispanos o novelistas, como Lope de Vega, Echegaray, Campoamor, Valera, Alarcón, Pardo Bazán, Núñez de Arce y Blasco Ibáñez, justamente a los diez años de conocerse en Corea las Aventuras de don Quijote. Todavía hoy existe la dificultad de leer obras en castellano debido a la escasez de textos, pero los nuevos hispanistas allanan las dificultades y traducen al coreano directamente porque ahora conocen y dominan nuestra lengua ${ }^{6}$.

La Universidad Hankuk de estudios Extranjeros de Seul, especializada en Lingüística extranjera moderna, establece en 1955, un Departamento o Sección dedicado al español. Aceptado por una minoría de alumnos, comienza para ellos un estudio "quijotesco", intentando conquistar a base de tenacidad y de ingenio, un mundo totalmente desconocido y dificultoso por la escasez de profesores, libros, periódicos o revistas... que hablen o escriban de "lo español". 1959 lanza los primeros licenciados especialistas en castellano. Se les considera "lunáticos". "¿Dónde y a quiénes van a enseñar el español estos nuevos diplomáticos?. ¿Qué familia querrá que sus hijos aprendan esta desconocida y lejana lengua?". Ampliando esta pequeña historia expongo el siguiente texto que me dirigio el Dr. Chang Sunion, en 1965:

Hace unos veinte años, la mayoria de los coreanos nos encontrábamos tan indiferentes de la existencia del español que creiamos que los paises iberoamericanos fueran de habla inglesa, por su relación geopolitica con los Estados Unidos. Pero, pese a tal incomprensión, habia un joven que estaba dispuesto a dedicarse toda su vida a la

6 Para conocer algunas de esas obras véase El español actual, Instituto de Cooperación lberoamericana, Madrid, 1984. 
expansión del idioma español, se llama l-Bae-Kim quien, desde muy temprano, presintiendo que el español sería tan importante y tan necesario como el inglés, habia venido estudiando dicha lengua entre la burla general. Naturalmente, su maestro, era un libro de español escrito en japonés y en inglés.

Por su esfuerzo constante y entusiasta, se abrió la Cátedra de Español en la Escuela de Lenguas Extranjeras, situada en Seul, capital de Corea, en 1947. Alli enseño el español a los estudiantes interesados o curiosos de dicha lengua, hasta que estalló la Guerra de Corea en 1950. Durante la guera, servia de consejero al Batallón de Colombia, uno de los paises miembros de las Naciones Unidas que asistieron a la mencionada guerra.

Después del cese del fuego, en 1954, se celebró el Acto Inaugural de la Academia de la Lengua Española en Corea, en presencia de ilustres personas y de los pocos hispanitas. En este acto fue elegido don Sung-Su Whang, Vicepresidente del Congreso Nacional, como Presidente; al señor I-Bae-Kim como Vicepresidente; y a la señora Young-Sin Im, rectora de la Universidad de Chungang, como consejera.

Las primeras actividades para expandir el español en Corea eran visiblemente notables: se abrian cursos de español periódicamente y varias universidades hispanoamericanas como la de El Salvador, la de México o la de Colombia, manifestaron que otorgarian becas a los estudiantes coneanos. Sin embargo muchos coreanos ignoraban que el español eran una lengua internacional.

En 1955 ocurrió un acontecimiento trascendental en la historia del español en Corea, salió a la luz la Sección de Lengua y Literatura Hispánicas en la Hankuk. University of Foreign Studies. Se encargó el profesorado al señor I-Bae-Kim en dicha sección. No cabe decir que los estudiantes estudiaban el español con el amor propio de ser los pioneros del idioma de Cervantes en Corea. Un año más tarde, llegó el señor don José Hahn a Corea, dejando Iras si Mexico, en el que habia pasado media vida de 50 años, para dedicarse a la educación del expañol hasta el resto de su vida. Sus conocimientos profundos y eruditos sobre la lengua y cultura hispánica encantó a todos los alumnos por completo. Especialmente su manera más racional de enseñanza del español, pues facilitó a los alumnos aprender dicho idioma.

En 1958, los alumnos pertenecientes a la Sección de Lengua y Literatura Hispánicas organizaron una reunión denominada "Investigación Cultural Hispanoamericana" con el propósito de estudiar politica, economia, costumbres o cuestiones de actualidad de España y de los diferentes paises iberoamericanos, teniendo discusiones e invitando a conferenciantes que habian hecho un viaje por los paises mencionados. Se distinguió el señor Rodriguez, senador de la República de México, quien hizo una conferencia sobre el tema "El progreso intelectual de hispanoamérica"; el señor embajador Villacieros con el tema "España"; el embajador de Costa Rica y otros...

En 1956 se dio a la luz un libro. El primer paso del Español escrito por el profesor I-Bae-Kim, quien ayudó a quienes ficran ansiosos de aprender el español y que sufrieron por no encontrar la ocasión. 
En 1959 se graduaron diez alumnos de la Universidad Hankuk de Estudios Extranjeros, tomando la borla de licenciados en Lengua y Literatura Hispánicas. Uno de ellos, llamado Kab-Dong-Cho se colocó en la emisora internacional "La voz de Corea Libre" como emisor de inglés, mediante oposiciones, pero su propósito era introducir el español y asi lo hizo?.

El señor Cho establece en 1961 un programa de radio, en español, dirigido a oyentes hispanohablantes a través de la emisora coreana Korean Broadcasting System $=\mathrm{KBS}=$ Radio Corea, emisión que perdura hasta hoy y que ha ampliado programas y horario para Europa e Hispanoamérica. En 1963, España reconoce esta creación otorgando el Premio "ONDAS" de la radio a este programa que a su vez vuelve a obtenerlo en 1964. Las relaciones diplomáticas con España se establecieron en 1950 y el 4 de enero de 1962 se nombraron los primeros embajadores, no residentes. Nuestro primer embajador en Corea con sede en Japón fue don Antonio Villacieros Benito y el de Corea en España, con sede en París, el señor Soo Young Lee, ambos ya fallecidos.

En 1963 y 1964 llegan a España algunos licenciados por la Universidad Hankuk. Amplian estudios y se doctoran más tarde en nuestras Facultades universitarias. Son preferidas en la Universidad Complutense, las Facultades de Filosofia y Letras, Periodismo, Ciencias Políticas y Bellas Artes. En otro ámbito, la Escuela de danza, Real Conservatorio de Música y Cursos de Música en Compostela. Algunos de estos estudiantes volverán a su patria y otros permanecen aquí hasta hoy. Muchos ocupan ahora puestos relevantes en la Función Pública de Corea o en la enseñanza universitaria. En la actualidad hay cerca de cinco mil alumnos de español repartidos entre la Universidad Hankuk de Seul y otras universidades del país. A su vez el bachillerato coreano ofrece el castellano como segunda lengua, aunque no tenga tantos adeptos como el inglés americano.

En 1964 era necesario contactar con amigos y personas simpatizantes de ambos países y redactamos las BASES de la primera Asociación Hispano-Coreana en Madrid, para la que encontramos una eficaz ayuda en el P. Félix Maria Pareja, fundador y secretario general de la Asociación Española de Orientalistas, la Asociación Hispano Coreana se fundó en 1967 y se ratificaron sus Estatutos el 25 de agosto de 1969. Mientras tanto, en Seul, una Asociación estudiantil llamada "El Álamo" reclamaba correspondencia con nuestros universitarios. Desde la Facultad de Filosofia y Letras y desde Radio Nacional de España que recoge la iniciativa, se establece un verdadero puente cultural de intercambio postal, de noticias y, sobre todo, de amistades. El programa de radio se titulaba "La Hora Joven" y estaba dirigido por el periodista don Juan Mayor de la Torre.

Me consta, y tengo documentación al caso, que otros organismos oficiales, como los Ministerios de Asuntos Exteriores, Educación y Ciencia, y el entonces Ministerio de Información y Turismo, así como Radio Nacional de España y Universidad Complutense de Madrid, no sólo contribuyeron en esta época a la difusión y ayuda de nuestra cultura tantas veces solicitada, sino que enviaron libros, folletos, películas, grabaciones de radio-novelas

7 Escrito del profesor Chang Sunion a la Prof. Roales-Nieto, en 1965, Colección particular de la firmante. 
y de teatro, mapas, carteles, etc. a la Universidad Hankuk de Seul: el día 24 de junio de 1966 se firmó el primer Convenio interuniversitario entre la Universidad Complutense y la Universidad Hankuk de Seul. Tuve el honor de intervenir personalmente en la redacción de las BASES junto al doctor Chang Sunion. El CONVENIO lo firmaron: el Dr. Federico Pérez Castro en representación del Rector Dr. Gutiérrez Ríos y el Dr. Chang Sunion en representación del suyo, Dr. Choi, Wan Bok. Este CONVENIO está en vigor actualmente y ha sido recientemente ratificado.

\section{DE MÚSICA Y SOBRE ASOCIACIONES ESPAÑOLISTAS E INTERCAMBIOS HISPANOCOREANOS}

La Música, lengua sutil y dificil, captado por la mente y el corazón en forma subjetiva y emocional, llegó también a Corea como mensaje de paz y de civilización hispánicas. Lo llevó a Seul un músico coreano, el primer coreano llegado a España en 1942. Los Festivales de Música celebrados en Seul en 1950 recibirán con sorpresa las composiciones de Manuel de Falla, Enrique Granados y Albéniz; se escuchan por primera vez dirigidos por Ricardo EAKTAY AHN (5 diciembre 1911 al 15 septiembre 1965), introductor. Este compositor y director de orquesta estudió en Japón y en Estados Unidos obteniendo el doctorado de Música por la Universidad de Filadelphia. Estudió con Bela Bartok, con Kodaly en Budapest y, en Viena, fue el único discípulo de Richard Strauss y vendrá a España para dirigir la Orquesta Nacional, la Sinfónica y la de Barcelona. Se quedó en España subyugado por nuestra música y el paisaje, casándose aquí, el 5 de julio de 1946, con una señorita (nacida el 3 de marzo de 1916) de Barcelona, Lolita Talavera, con la que tuvo tres hijas. Ella supo hacer ver y comprender a Eaktay las bellezas de nuestra patria, encontrando ambos en las Baleares (Mallorca) el lugar residencial para su matrimonio, y los temas más hermosos de inspiración para sus composiciones más notables: Poema a Mallorca, Sinfonia Balear o El Pino de Formentor.

Lolita Talavera en su libro Mallorca y Eaktay Ahn narra cosas entrañables a propósito de su marido en la isla de la calma:

"(...) Tener una orquesta en esta isla es como tener un lugar en el cielo" ( $p p .144$ y ss.). (...) Cuando Strauss vea esta isla, no querrá irse de aqui (p.85).

Transcribo a continuación un artículo publicado en los diarios mallorquines a propósito del poema sinfónico "Mallorca" en el que nuestro AHN justificaba la composición de su obra:

"Al llegar a Mallorca, lo primero que me impresionó profundamente fueron sus hermosas montañas, sus colinas, su mar y el agradable panorama de su paisaje; todo ello, poesia de la Naturaleza, me brindó la inspiración más alta. Como músico lo que particularmente me cuasó honda impresión fue la riqueza inmensa de la música folklórica" (...)

8 Eaktay AHN estudió con Bela Bartok, Kodaly en Budapest, en Viena con R. Strauss, etc. 
"Esta música viene directamente del corazón y del alma de hombres y mujeres de Mallorca, expresa su amor a la tierra y permanecerá como uno de los más preciados tesoros en el futuro de la cultura mallorquina y de España. El poema sinfónico "Mallorca" me fue inspirado por estas bellezas" (...)

Este poema sinfónico se estrenó en Palma de Mallorca en octubre de 1948. El maestro AHN al frente de la Orquesta de Palma dejó huella de su quehacer musical resucitando las composiciones olvidadas de autores mallorquines haciéndolas sonar en la Orquesta e incorporándolas al repertorio sinfónico.

Aparte de esta música "en vivo", no quiero dejar de resaltar la importancia que en la difusión de la cultura española tuvo Radio Nacional de España, cuyo director entonces, don Jesús Aparicio Bernal, permitió al periodista coreano, señor Cho, Kab-Dong, el envío a las difusoras de su pais: KBS y DONG-A, un programa semanal de una hora, sobre música, actualidades y hechos sobresalientes de la vida española; programas realizados sin interrupción desde 1964 a 1971. (Radio Nacional de España admite desde entonces periodistas becarios en relación de reciprocidada con la emisora KBS y con la emisora de televisión coreana). Pienso que de aquí parte la afición del pueblo coreano por España y su gusto por la música más popular y representativa: la guitarra, el flamenco, las castañuelas, los toros... y de aquí parte también el fomento y el interés hacia estos estudios en España de guitarristas y bailarines coreanos. Yo misma en mi recorrido por las universidades coreanas en 1985 , tuve que enseñar a tocar las castañuelas, aunque solamente sepa hacerlas sonar, los estudiantes hispanistas parecían conquistar el misterio de España y comprender en un momento la alegria del mundo goyesco del que sus profesores españoles hablaban.

Desde 1966 hay constantes misiones especiales a España para intervenir en los concursos internacionales de formción profesional obrera para solicitar el voto de España en las Naciones Unidas, vienen los diputados coreanos, armadores de buques, hombres de negocios, políticos, comerciantes, ministros y otras personalidades de la enseñanza, la diplomacia y las artes. También bienen los directores de cine, les interesan los toros, las procesiones de Semana Santa, la gastronomía y el baile flamenco. En 1967, se elige a D. Luis de la Serna y Espina, primer cónsul honorario de Corea en España. Un año más tarde se abrirán los consulados de Canarias, Barcelona y Lisboa. También en ese mismo año llegará a España una misión especial presidida por el señor KIM, Yong-Pil, primer ministro de Corea. La Asociación Española de Orientalistas ofrece una recepción extraordinaria y le otorga el Título de Miembro de Honor, en una sesión solemne.

En 1970 se creó en Seul la "Koream Spanish Association" con bases similares a las proyectadas por nosotros años antes. Fecha de la creación, 20 de enero. Primera Asamblea General y elección de presidente el 4 de febrero del mismo año.

El once de abril de 1970, se abre la primera Embajada de Corea en España con sede permanente en Madrid. Primer embajadork, el Dr. CHOI, Wan-Bok, siendo el actual embajador en la sucesión, el señor Jang-Hee-Hong.

En Corea se otorgó el Premio Nacional de Traducción, "PEN", al primer doctor coreano en Lenguas Románicas por la Universidad Complutense, señor Chang Sunion. Su obra es la versión al coreano de "Don Quijote de la Mancha". 
Desde entonces, el Departamento de Español de la Universidad Hankuk que dirigió el Dr. KIM, I-Bae, ha publicado versiones directas de nuestros escritores más renombrados: Lope, Quevedo, Juan Ramón Jiménez, Camilo José Cela, Delibes, Alberti, hermanos Machado, Díaz-Plaza y otros, además de una serie de diccionarios bilingües de gran utilidad, incluso se ofrecen desde 1975 lecciones de Español por radio, y desde 1981, por televisión. El actual director del Departamento, Dr. PARK, Chul, tradujo también "El Quijote" y presentó en los Congresos de la Asociación de Cervantistas preciosos textos traducidos de los "Entremeses Cervantinos" (Mahón, El Toboso y Villanueva de los Infantes).

1972 nos ofrece la novedad de que en el Instituto de Enseñanza Media "Lope de Vega" de Madrid, se haga un curso opcional sobre civilización coreana para las alumnas de COU, curso que organicé e impartí yo misma. Al acto de Clausur del citado curso, presidido por el Director del Centro, D. Ángel Cabetas, asistió el Embajador de Corea, Dr. CHOI, WanBok, quien pronunción una magnífica conferencia titulada "Don Quijote en Corea".

La embajada de España en Seul se inaugura el 22 de octubre de 973 . Su embajador será don José María Aguado Saralegui. Le sucederá don Ramiro Pérez Maura, quien impulsa la cultura española en Seul y abre una Biblioteca de Estudios Hispánicos y un Salón de Actividades. Le sucedió en el cargo D. Fermín Prieto Castro y es éste el actual embajador.

Y para terminar, diré que existe la Asociación de Hispanistas Asiáticos con sede en Seul. Que se celebró un Congreso Internacional bajo su dirección en junio de 1985 al que asistieron más de 200 profesores hispanistas de Extremo Oriente. El tema de estudio siempre de actualidad en Corea fue: "El Quijote en Asia", y otros temas relacionados con la Historia, la Cultural, la Lingüística y la Literatura de España.

Los licenciados en español han aumentado considerablemente. En Corea estudian nuestra lengua más de tres mil personas. En España hay más de cinco mil coreanos: unos estudian en la Complutense, en Barcelona o en Salamanca, otros se doctoran, estudian en Conservatorios de Música, en las Facultades de Bellas Artes, de Ciencias de la Información. Otros son residentes aquí y sus preferencias son varias: deporte Taekwondo, Artes Marciales, granjas avícolas, restaurantes, la enseñanza, la diplomacia o el comercio.

Aquel pequeñísimo núcleo de estudiosos, es ahora el cuerpo profesoral de la Universidad Hankuk o de otras catorce universidades, son altos funcionarios del Estado coreano, diplomáticos en los Ministerios de su pais, o en Iberoamérica. Alguno de ellos, incluso, escribe y enriquece nuestra hermosa Lengua española con hermosas y delicadas poesías en español. Es el caso excepcional del Dr. MIN, Young-Tae, doctorado en Literatura Española por la Universidad Complutense.

El interés y el estudio de lo Hispánico en Corea es notoriamente ascendente y aumenta conforme se adquiere en el país, crecimiento económico y financiero. "Don Quijote de la Mancha" es y será el leit motif de los estudios de Literatura Española, acompañados ahora por los poetas y los sabios, los músicos y los artistas, los medios informativos y las cámaras de televisión.

Ahora, Corea se basta a sí misma y coopera con el mundo superando las tragedias y el dolor de las etapas antiguas mostrándonos el esplendor de su recuperación espiritual y material. Lo esenecial es vivir y convivir en paz. Crear y recrear intelectuales, artistas y depor- 
tistas. En una palabra, demostrar la existencia auténtica de este "pais de las mañanas en calma". En España hay una reciprocidad, un interés hacia lo coreano y su mundo, pero este aspecto del que también hay mucho que hablar y en el que toma parte activa la Asociación Española de Orientalistas y los fundadores de la Asociación Hispano-Coreana lo dejaremos para otra ocasión.

En Corea, más conocida ahora por la realización en su suelo de los Juegos Olímpicos, se desea colaborar y estudiar las relaciones internacionales con todo el mundo hispánico, que, demás, puede ofrecer seguridad, aposento y trabajo y no dudamos de que este mundo hispánico nuestro es un campo muy grande para realizarse en cualquiera de sus facetas.

\section{ÚLTIMOS DATOS CULTURALES RELATIVOS A LO ESPAÑOL FACILITADOS POR EL MINISTERIO DE ASUNTOS EXTERIORES}

\section{Datos sobre la enseñanza del Español en Corea}

- Número de Universidades Surcoreanas con Departamento o con Sección de Español: 14. En ellas imparten clase 75 profesores, 10 de ellos españoles.

- Número de Centros de Enseñanza Media en los que se imparte el Español: 32. En ellos imparten clase 53 profesores, uno de ellos español.

- Número de Academias privadas de Español: 5. En ellas trabajan 6 profesores de español, todos ellos coreanos.

\section{Actividades culturales en la Embajada de España en Seul en 1998}

- Existen también unas becs de curso académicos completo cuyo cupo para Corea es de 11 , a la que aspiraron 31 candidatos.

- Por otro lado, a primeros de 1998 concluyó el contrato que la lectora de español tenía con la Universidad Nacional de Seul. La mitad de la financiación del lectorado corre a cargo de la Embajada.

- Los exámenes del Diploma de Español como Lengua Extranjera (DELE) se celebraron como es habitual en mayo y noviembre, se presentaron 55 candidatos en total, y, en mayo, 96 lo que arroja un total de 151.

Actividades culturales con participación o ayuda económica de la embajada

1) 7-9 de marzo, feria promoción estudios lingüísticos en el extranjero.

2) Marzo, ciclo de cine español en la Universidad HANKUK.

3) Abril, representación teatral en la Universidad Nacional de Seul de la obra Los viejos bauiles empolvados, de Carlos J. Reyes.

4) 2-12 de septiembre, ciclo de conferencias del profesor Eguren de la Universidad Autónoma de Madrid sobre lingüistica hispánica en Seul y otras ciudades coreanas. 
5) 18-21 de septiembre, festivales de arte hispánico en Universidad Hankuk.

6) 25-26 de octubre, Cuarta Feria de Estudios en el Extranjero.

7) Octubre, envio de fondos documentales sobre el P. Céspedes (jesuita español que en el s. XVI fue el primer occidental en llegar a Corea) al Museo Nacional de Chinhas.

8) 20 de noviembre, inauguración dedicada a España de grandes almacenes "Shinsegae" en Inchón.

9) 2 de diciembre, feria de promoción en Asia del turismo español en el hotel "Westin Chouson" para la que se desplazó a Seul el agregado de turismo residente en Tokio, Sr. Renedo.

\section{Actividades culturales 99 (encro-septiembre). Embajada de España en Seul}

1) 19-21 de marzo: Feria del estudiante Primavera 99, Promoción de estudio del español como lengua extranjera en España.

2) 19 de abril: Charla en la Universidad Hankuk de Estudios Extranjeros sobre el estado de la lengua española en el mundo.

3) 25 de abril: Conferencia en la Embajada del profesor Sookyoung Yoon, catedrático de la Universidad Hankuk de Estudios Extranjeros y Presidente de la Asociación Coreana de Hispanistas sobre el estado del español en Corea.

4) 26 de abril: Presencia en el acto de apertura del Segundo Congreso Internacional sobre Formación Profesional, organizado por el Ministerio de Educación Coreano y la UNESCO.

5) 3 de mayo: Charla sobre DELE y cultura española en general a cadetes que han elegido español como lengua extranjera en Academia Militar del Ejército (Seul).

6) 3 de junio: Charla en la Embajada de la profesora Chavel, de la Universidad "Antonio de Nebrija" sobre metodología de la enseñanza del español como lengua extranjera.

7) 21 de junio: Conferencia en la Embajada sobre Gregorio de Céspedes y el primer encuentro España-Corea a cargo del profesor Park Chul, catedrático de la Universidad Hankuk de Estudios Extranjeros.

8) 29 de julio: Concierto del guitarrista español, José Luis Rodrigo, organizado por la Universidad Yonseei de Seul.

9) 4-5 de septiembre: Feria del estudiante Otoño 99. Promoción de estudio del español como lengua extranjera en España.

10) 4 de septiembre: Representación de la obra de teatro, "la Chunga" de Mario Vargas Llosa por estudiantes de la Universidad de Corea (Subvencionada en parte por la Embadaja).

11) 8 de septiembre: Recital "Dúo Cervantes" de Alcalá de Henares en una sala de conciertos de Seul. Se interpretaron obras de Turina, Falla, Nin y Sarasate.

12) 10 de septiembre: Recital de Arpa por Maria Rosa Calvo Manzano (obras del Renacimiento Español y propias de la Arpista). 
P.D.: Hasta aquí los datos (en síntesis) que tenemos de lo español en Corea. Recientemente los Reyes de España han visitado Seul para estrechar las relaciones Hispano-Coreanas.

Para otros datos (financieros, comeciales, tecnológicos, deportivos, etc.) consúltense los archivos de la Embajada de Corea en Madrid.

Hoy mismo, 20 de octubre, visita Corea el Presidente Español, tratando entre otros asuntos importantes, del reconocimiento del Norte de Corea, primer paso para la reunificación del pais. Merecido el premio Nobel de la Paz al presidente actual del País.

Tengo programada una "semana" sobre Corea a principios de marzo próximo.

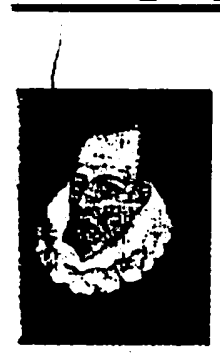

이세르밤테스

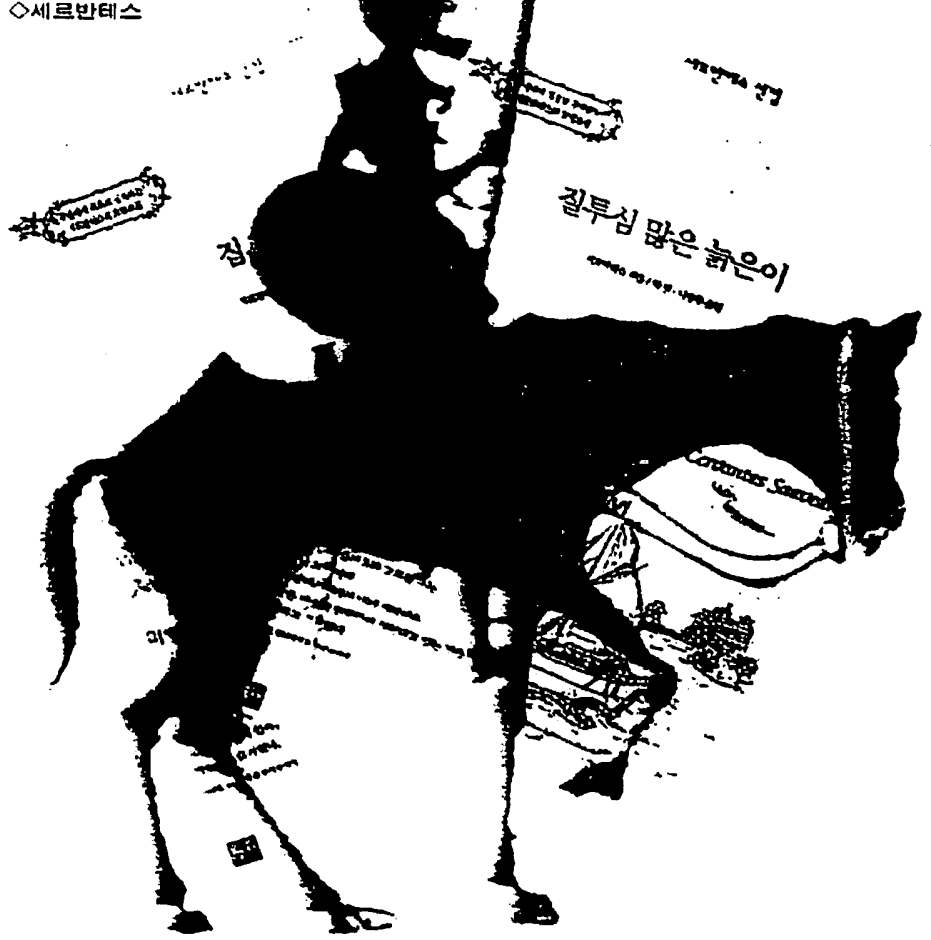

문학

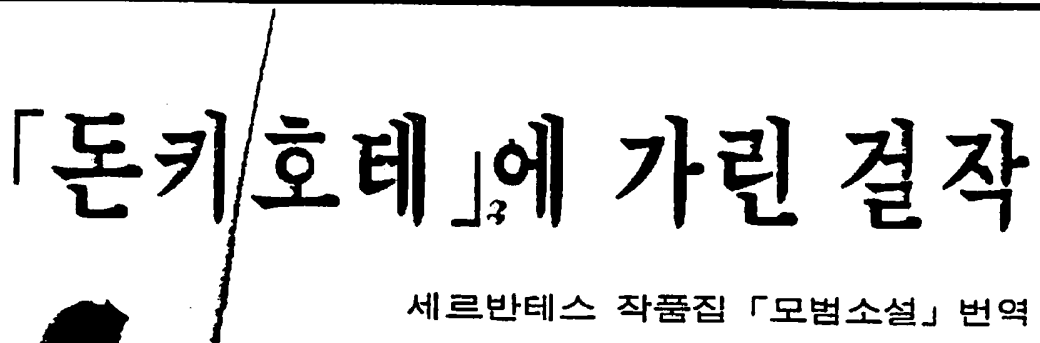

스페인의 분호 새르반테스으 「도변소섬 J이 나왔다. 현닌쬬 촐 조한 세이스피어와 감리 미귬 더 세르반테스른 자기 소셤의 후은 공 돋키호테에 가려진 작가다. 란생 450주년웜 기녑하여 이방 에 번영된 $r$ 모변소설 핵)은 1613년 세르반테스가 내홓 온 12개의 풍단편 모읍. 이백이 난행딘 1.2권에 이어 연맙가지 드후 6 진이 쿡내에 소개횐다.

가독키호테,는 스페인에서조차 완댁한 사단이 트뮬 점도로 어협

\section{다양한 소설기}

\section{괴테도 “교훈 :}

습니다. 난해한 작항이라는 확먼 초 있지만, 충차금 항해 단려가 놀 자아도회의 인율형으로 너무 유명해 정자 소성로 제대로 인은 사밥온 없조.J 벙연윤 흐도란 반 천(외뎨 서반아어고)교수를 범소설 이 사르반테스의 진면돈 윤 알리기화 기대한다고 앖샜다. 이 작중욘 1605년 현간된 흘 키호테 11 편과 1615 넌 반표된 - 플 키로텨 12펴 사이에 훈간뻤다. $6 E$ 세의 세르반테스는 $r$ 돌키호터 에 서 밤 수 없었뎐 다양한 소색기 밥을 여기서 선보이고 있다. "도

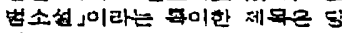

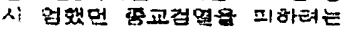
의도도 있지만, ㄱㅇ이것균 인른 한 자가 나쓴 족당욜 중제쾩다변 거 


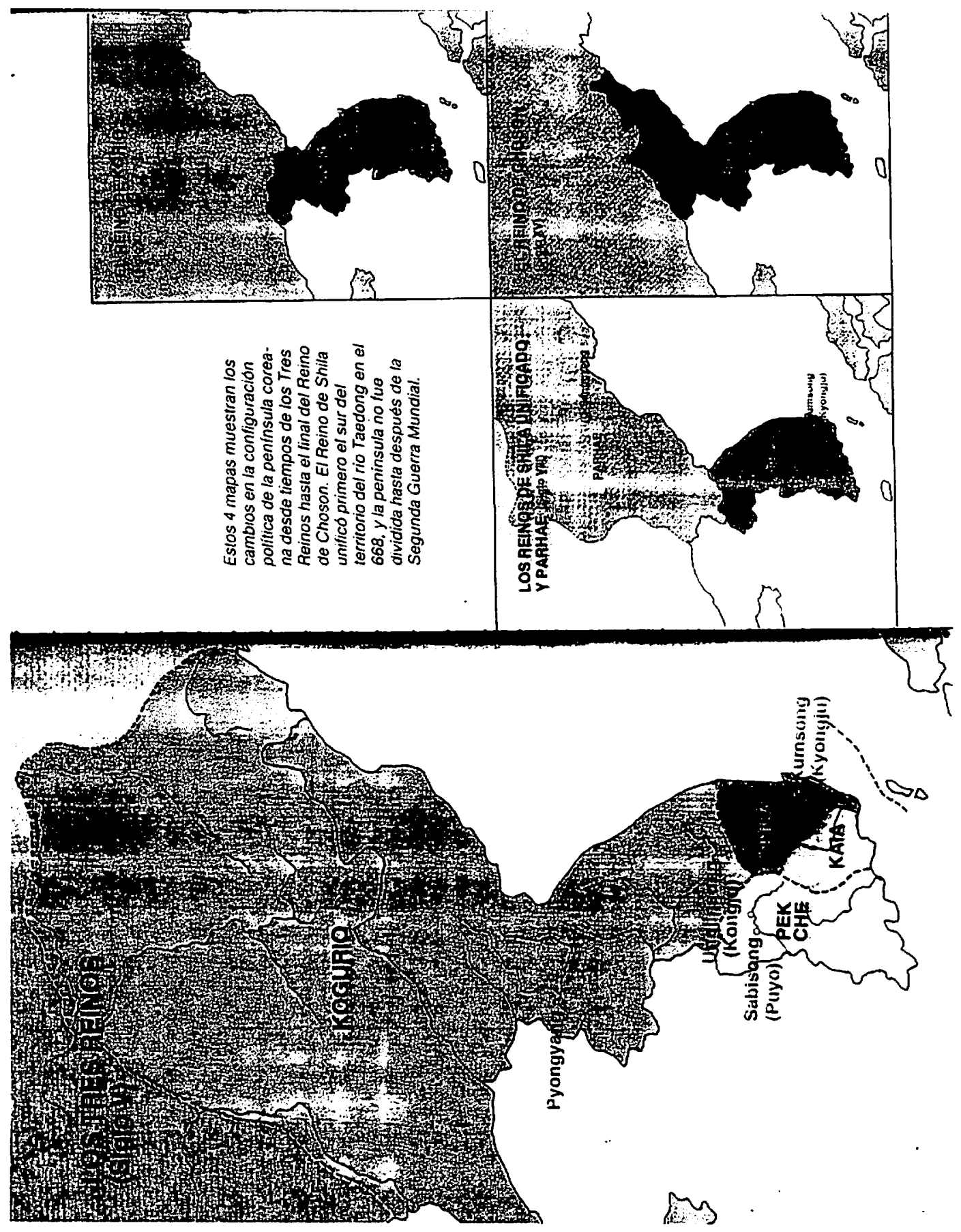

